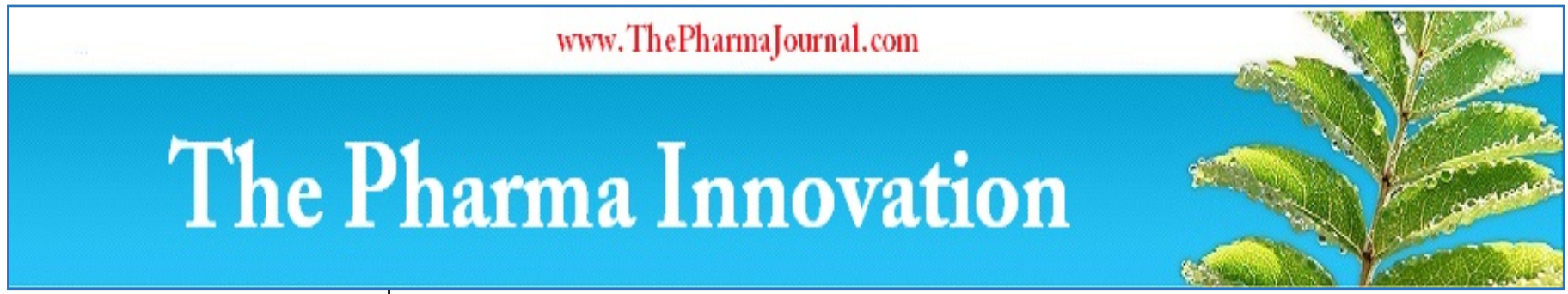

ISSN (E): 2277 - 7695

ISSN (P): 2349-8242

NAAS Rating: 5.03

TPI 2020; 9(11): 346-348

(C) 2020 TPI

www.thepharmajournal.com

Received: 21-08-2020

Accepted: 05-10-2020

Malleshappa C

Associate Professor, Breeder,

$\operatorname{AINP}(\mathrm{T}), \mathrm{ZAHRS}, \mathrm{UAHS}$,

Shivamogga, Karnataka, India

Sowmya TM

Assistant Professor, Agronomy, AINP (T), ZAHRS, UAHS,

Shivamogga, Karnataka, India

Priyanka SR

Assistant Professor, Agronomy, AINP (T), ZAHRS, UAHS,

Shivamogga, Karnataka, India

Mutturaj Dhavaleshvar

Assistant Professor, Agronomy, AINP (T), ZAHRS, UAHS,

Shivamogga, Karnataka, India

Corresponding Author:

Priyanka SR

Assistant Professor, Agronomy,

AINP (T), ZAHRS, UAHS,

Shivamogga, Karnataka, India

\section{Genetic diversity studies on leaf yield and its component traits in FCV tobacco (Nicotiana tobacum L.) germplasm collection}

\author{
Malleshappa C, Sowmya TM, Priyanka SR and Mutturaj Dhavaleshvar
}

DOI: https://doi.org/10.22271/tpi.2020.v9.i11f.5377

\section{Abstract}

The present study was aimed to assess the extent of genetic diversity with sixty-six genotypes of FCV tobacco (Nicotiana tobacum L.) by using Mahalanobis' $D^{2}$ statistics at AINP (Tobacco), Zonal Agriculture and Horticultural Research Station, UAHS, Shivamogga, Karnataka during Kharif-2019-20 in RCBD design with two replications. The 66 genotypes were grouped into eight clusters based on $\mathrm{D}^{2}$ analysis. The cluster II had maximum with 29 genotypes followed by clusters I, III, V, and IV had the minimum with 16, 16, 8 and 5 genotypes respectively and remaining clusters were solitary. The highest inter cluster distance was observed between cluster VI and VIII and the lowest between clusters II and VIII. Cluster V had exhibited highest intra cluster distance and the lowest was observed in cluster VI, VII and VII. The character days to flowering, top grade equivalent and green leaf yield showed maximum contribution towards total genetic divergence. On the basis of cluster mean, cluster VI was superior for plant height, number of leaves per plant and leaf length. The maximum leaf width was observed in cluster VIII, while cluster VII sowed superiority for days to flowering. The cluster IV showed highest green leaf yield, cured leaf yield and top grade equivalent. Thus, the genotypes involved in these clusters may be taken into consideration for better parents for generating variability for the respective characters and their rational improvement.

Keywords: Nicotiana tabacum, Genetic diversity, $D^{2}$ statistic, Cluster analysis, Germplasm

\section{Introduction}

Tobacco (Nicotiana tabacum L.) is a member of nightshade family, Solanaceae with chromosome number $2 n=2 x=48$. Tobacco is one of the few crops entering world trade entirely on a leaf basis and the most widely grown commercial non-food plant in the world. There are more than 70 species in the Nicotiana genus, but only two species of Nicotiana (Nicotiana tabacum L. and Nicotiana rustica L.) are widely grown commercially all over the world. Genetic divergence analysis helps in accessing the nature of diversity in order to indentify the genetically diverse genotypes for their use in plant breeding programme. Selection of diverse parents for productive heterosis is of paramount importance since heterosis was to dependant on the extent of genetic diversity between the parents (Moll et al., 1965) ${ }^{[5]}$. The pattern of distribution of genotypes in different clusters exhibited that geographical diversity was not related to genetic diversity as genotypes of same geographical region were grouped into different cluster and vice-versa (Dobhal et al., 1989) ${ }^{[2]}$. The multivariate analysis by means of Mahalanobis' $\mathrm{D}^{2}$ statistic helps in quantifying the degree of divergence between biological population at genotypic level and also to assess the relative contribution of different components to the total divergence both at inter and intra cluster level. Therefore an attempt was made in the present investigation to assess the extent and nature of genetic diversity among eight characters in 66 genotypes pertaining to yield and yield attributing characters.

\section{Materials and Methods}

The experimental material of present investigation comprised of sixty-six genotypes of FCV tobacco were grown in a randomized complete block design with two replications during 2019-20 of kharif season at AINP (Tobacco), ZAHRS, University of agricultural and horticultural sciences, Shivamogga, Karnataka. Each replication consisted of a single row of 10 plants. Spacing from row to row and from plant to plant was $60 \mathrm{~cm}$ and $30 \mathrm{~cm}$ respectively and the crop was raised as per the recommended package of practices. Observations on plant height, number of leaves per plant, leaf length, leaf width, days to flowering, green leaf yield, cured leaf yield and top grade equivalent were studied on five random plants on each genotypes. 
Genetic Divergence analysis was calculated by using formula suggested by Mahalanobis, $1936^{[4]}$. Clustering of genotypes using $D^{2}$ values followed by Tocher's method (Rao 1952) ${ }^{[7]}$.

\section{Results and Discussion}

Improvement in green leaf yield is normally attained through involvement of the genetically diverse parents in breeding program. For identifying such diverse parents for crossing, Mahalanobis' $\mathrm{D}^{2}$ statistic was used in present research. Grouping of the genotypes was carried-out by the Tocher's method (Rao, 1952) ${ }^{[7]}$ with the assumption that the genotypes within cluster have lesser $\mathrm{D}^{2}$-values among themselves than those from groups belonging to different clusters.

Among all clusters (Table 1), cluster II was largest with 18 genotypes followed by cluster II and III with 16 genotypes each, cluster V contains 8 genotypes and cluster IV contains 5 genotypes. The remaining clusters VI, VII and VIII were all solitary clusters with single genotypes. Similarly, 40 genotypes of bidi tobacco (Nicotiana tabacum L.) on eight yield and yield attributing characters were grouped into 12 clusters by Parmar et al., $2004^{[6]}$. Further, Amarnath, $1989^{[1]}$ studied thirty-eight strains of chewing tobacco (Nicotiana tabaccum L.) for genetic divergence for nine yield contributing characters through multivariate analysis and grouped into 12 clusters. Suman Parajuli et al., 2015 [8] carried out similar type of diversity study in 40 genotypes of bidi tobacco using Mahalanobs' $\mathrm{D}^{2}$ statistic and grouped genotypes into 16 clusters. From the above, it could be concluded that pattern of distribution of genotypes among various clusters reflected the considerable genetic diversity present in the genotypes under study.

Table 1: Grouping of sixty-six genotypes on the basis of Tocher's method

\begin{tabular}{|c|c|c|}
\hline Clusters & No. of genotypes & Name of the genotypes \\
\hline I & 16 & $\begin{array}{l}\text { Delcrest-66, L1136, JS117, Adcock, A-23, CU-387, Samsar-940, KST-7, GK-149, Vinca-5, NC-729, } \\
\text { IS129, Vamorr-50, YELLOW GOLD, PCT-8 and 6-6 RMS }\end{array}$ \\
\hline II & 18 & $\begin{array}{l}\text { COKER-176, V-4955, NC-37 NF, Thrupthi, Dixic Bright-101, Coller -547, Spt.G-140, Bright capsule\#2, } \\
\text { TI-1112, Golden wilt, NC-567, YELLOW SPECIAL A, NC-60, YELLOW SPECIAL, TI-448A, EC- } \\
\text { 554900, Olior-10 and V-4848 }\end{array}$ \\
\hline III & 16 & $\begin{array}{c}3127 \text { (Albacueulatcy), TANTA, V4219, NC-606, GSH-2, Golden cure, Hicks, VESTA-5, NC-207, } \\
\text { Nambiar, MC-1, Coller -3719, Yellow gold, Maryland, HE-2 and EC-554926 }\end{array}$ \\
\hline IV & 5 & Kanchan, Sahyadri, PYKY-160, L621 and GL-939 \\
\hline $\mathrm{V}$ & 8 & EC-55429, EC-554930, VA-116, Y-156, K-317, VA-115, TI-836 and T 1 -832 \\
\hline VI & 1 & F-220 \\
\hline VII & 1 & NC-13 \\
\hline VIII & 1 & K-399 \\
\hline
\end{tabular}

Hybridization of genotypes belonging to the same cluster is not expected to yield superior hybrids or desirable segregants. However, theoretically a general notion exists that the larger is the divergence between the genotypes, higher will be the heterosis (Falconer 1981) ${ }^{[3]}$. Therefore, it would be desirable to attempt crosses between genotypes belonging to distant clusters for getting highly heteroitic crosses. In this context, inter and intra-cluster distance (Table 2) were worked out considering the eight characters. The highest inter- cluster distance 306.01 was found between cluster VI and VII, followed by 228.00 between VI and VIII. The minimum intercluster distance 45.52 was observed between cluster II and VIII. The intra- cluster distance ranged from 12.79 (cluster- I) to 43.15 (cluster-V). The three clusters (VI, VII and VII) composed single genotype each and therefore, between these genotypes intra- cluster distances was zero. The genotypes grouped into same cluster displayed the lowest degree of divergence from one another and in case crosses made between genotypes were belonging to the same cluster, no transgressive segregant is expected from such combinations. Similarly, Sunil et al., $2016^{\text {[9] }}$ reported that intra-cluster distances in all the eleven clusters were more or less similar (closely related), than genotypes belongs to inter cluster. The highest inter-cluster distance was observed between cluster IV and cluster IX and the lowest between the cluster III and VIII. Therefore, hybridization programmes should always be formulated in such a way that the parents belonging to different clusters with maximum divergence could be utilized to get desirable transgressive segregants. The genotypes with high values of any cluster can be used either for direct adoption or for hybridization, followed by selection.
Table 2: Average Intra (diagonal) and Inter cluster $\mathrm{D}^{2}$ values among eight clusters in tobacco genotypes

\begin{tabular}{|c|c|c|c|c|c|c|c|c|}
\hline Clusters & I & II & III & IV & V & VI & VII & VIII \\
\hline I & 12.79 & 48.85 & 70.58 & 58.61 & 188.42 & 182.79 & 59.17 & 62.30 \\
\hline II & & 23.90 & 75.56 & 51.85 & 176.02 & 191.58 & 64.19 & 45.52 \\
\hline III & & & 36.57 & 66.85 & 90.06 & 65.62 & 135.50 & 92.94 \\
\hline IV & & & & 31.11 & 200.35 & 134.12 & 140.64 & 116.59 \\
\hline V & & & & & 43.15 & 88.44 & 213.00 & 148.70 \\
\hline VI & & & & & & 0.00 & 306.01 & 228.00 \\
\hline VII & & & & & & & 0.00 & 48.21 \\
\hline VIII & & & & & & & & 0.00 \\
\hline
\end{tabular}

Contribution of each character towards genetic divergence has been estimated (Table 3) that days to flowering contributed the maximum of 45.55 per cent towards the genetic divergence followed by top grade equivalent (24.99). Green leaf yield (21.59), plant height (3.08), cured leaf yield (2.52) and leaf length (1.45) shown moderate to low contribution to genetic diversity while, leaf width (0.75) and number of leaves per plant (0.09) contributed negligible towards the total divergence in yield. Among these characters, the highest contributor was days to flowering followed by top grade equivalent indicating the major role of these characters in differentiating of inter cluster levels. Similar observations have been recorded by Suman Parajuli et al., $2015^{[8]}$ in bidi tobacco. The above results imply that in order to select genetically diverse genotypes for hybridization, the material should be screened for the important traits like days to flowering followed by top grade equivalent, green leaf yield and plant height. 
Table 3: Per cent contribution of different characters towards genetic divergence

\begin{tabular}{|c|c|c|}
\hline S. No & Characters & \% Contribution \\
\hline 1 & Days to flowering & 45.55 \\
\hline 2 & Top Grade Equivalent & 24.99 \\
\hline 3 & Green leaf yield (g/plant) & 21.59 \\
\hline 4 & Plant height (cm) & 3.08 \\
\hline 5 & Cured leaf yield (g/plant) & 2.52 \\
\hline 6 & Leaf length (cm) & 1.45 \\
\hline 7 & Leaf width (cm) & 0.75 \\
\hline 8 & Number of leaves per plant & 0.09 \\
\hline
\end{tabular}

On the basis of cluster mean, cluster VI (Table 4) was superior for plant height $(108.75 \mathrm{~cm})$, number of leaves per plant (19.00) and leaf length $(55.75 \mathrm{~cm})$ and lowest mean values for days to flowering (91.00). The maximum leaf width $(35.50 \mathrm{~cm})$ was observed in cluster VIII, while cluster VII shown superiority for days to flowering (124.00). The cluster IV showed highest green leaf yield (9964.31 g /plant), cured leaf yield (1377.64 g/plant) and top grade equivalent (742.46). Hence, it is worthy to note that in calculating cluster means, the superiority of particular genotype in respect at a given character get diluted by other genotype that are related and grouped in the same cluster but which are inferior or intermediary for that character in question. Hence, apart from selecting genotypes from the clusters which have high intercluster distance for hybridization, one can also think of selecting parents based on extent of genetic divergence in respect to a particular character of interest.

Table 4: Cluster means for eight characters in tobacco genotypes estimated by Tocher's method

\begin{tabular}{|c|c|c|c|c|c|c|c|c|}
\hline Cluster & $\mathbf{X}_{\mathbf{1}}$ & $\mathbf{X}_{\mathbf{2}}$ & $\mathbf{X}_{\mathbf{3}}$ & $\mathbf{X}_{\mathbf{4}}$ & $\mathbf{X}_{\mathbf{5}}$ & $\mathbf{X}_{\mathbf{6}}$ & $\mathbf{X}_{\mathbf{7}}$ & $\mathbf{X}_{\mathbf{8}}$ \\
\hline I & 78.19 & 14.59 & 38.28 & 21.59 & 120.94 & 6935.32 & 1282.55 & 641.27 \\
\hline II & 88.01 & 15.64 & 44.57 & 22.53 & 120.83 & 7688.54 & 1100.57 & 656.80 \\
\hline III & 99.05 & 16.47 & 48.38 & 22.88 & 106.06 & 7229.59 & 1202.73 & 634.71 \\
\hline IV & 95.00 & 16.30 & 42.70 & 19.75 & 117.80 & 9964.31 & 1377.64 & 742.46 \\
\hline V & 104.44 & 15.69 & 43.47 & 24.13 & 91.38 & 4062.50 & 1028.50 & 601.73 \\
\hline VI & 108.75 & 19.00 & 55.75 & 23.25 & 91.00 & 8385.42 & 1326.16 & 663.08 \\
\hline VII & 66.00 & 11.50 & 36.50 & 11.00 & 124.00 & 4637.50 & 772.23 & 463.34 \\
\hline VIII & 84.75 & 14.00 & 52.25 & 35.50 & 119.50 & 4776.16 & 867.59 & 520.56 \\
\hline
\end{tabular}

$\mathrm{X}_{1}$ = Plant height $(\mathrm{cm})$

$\mathrm{X}_{2}=$ Number of leaves per plant

$\mathrm{X}_{3}$ = leaf length $(\mathrm{cm})$

$\mathrm{X}_{7}=$ Cured leaf yield (g/plant)

$\mathrm{X}_{5}=$ Days to flowering

$\mathrm{X}_{6}=$ Green leaf yield (g/plant)

Therefore, from the $\mathrm{D}^{2}$ analysis of genetic diversity, based upon high yielding genotypes and large inter- cluster distances, it is advisable to attempt crossing of the genotypes from cluster IV and cluster VI as parents in hybridization programme for generating variability for the respective characters, and their rational improvement for increasing leaf yield.

\section{References}

1. Amarnath S. Genetic divergence in chewing tobacco. Tob. Res 1989;16:25-8.

2. Dobhal VK, Murthy NS, Nageswara Rao CR. Genetic divergence in hookah and chewing tobacco (Nicotiana rustica L.). Tob. Res 1989;15:104-107.

3. Falconer DS. Introduction of quantitative genetics. 2nd Edition. Oliver and Boyd, Edinburg London, 1981, 164176p.

4. Mahalanobis PC. On the generalized distance in statistics. Proc. Nat. Inst. Sci. India 1936;2:49-55.

5. Moll RH, Lonnquist JH, Fortuna JV, Johnson EC. The relation of heterosis and genetic divergence in maize. Genetics 1965;52:139-144.

6. Parmar DJ, Patel AD, Kher HR, Makwana MG, Patel JN. Genetic divergence in bidi tobacco (Nicotiana tabacum L.). Tob. Res 2004;30(2):149-153.

7. Rao CR. Advanced Statistical methods in Biometric Research, John Wiley \& Sons. New York, 1952, 357361p.

8. Suman Parajuli DA, Patel MG, Makwana, Parmar DJ. Genetic diversity studies on cured leaf yield and its components in rustica tobacco [Nicotiana rustica (L.)]. Trends in Biosciences 2015;8(7):1753-1757.

9. Sunil MG, Mohan Kumar HD, Mohan Kumar NV. Genetic diversity for seed and oil yield in chewing tobacco (Nicotiana tabacum L.) germplasm collections.

Research Journal of Agricultural Sciences 2016;7(2):44644. 